\title{
ELECTROCHEMICAL INVESTIGATION OF CYSTEAMINE AT CARBON FIBER MICRODISK ELECTRODE
}

\author{
I S EL-HALLAG', A.O. AL-YOUBI ${ }^{2}$, A.Y. OBAID², E.H. EL-MOSSALAMY', S.A. EL-DALY', AND A.M. ASIRI \\ ${ }^{1}$ Chemistry Department, Faculty of Science, Tanta University, Tanta 31527, Egypt \\ ${ }^{2}$ Chemistry Department, Faculty of Science, King AbdulAziz University, P.O. Box 80203, Jeddah, Saudi Arabia
}

(Received: September 23, 2010 - Accepted: October 11, 2011)

\begin{abstract}
The electrooxidation of cysteamine compound was carried out using convolutive cyclic voltammetry, linear sweep voltammetry and chronoamperomtry techniques at a carbon fiber microdisk electrode in $0.1 \mathrm{M}$ perchloric acid. The electrooxidation potential $\left(E^{0^{\prime \prime}}\right)$ of cysteamine occurs at $+0.921 \mathrm{~V}$. The mechanistic pathway of electrooxidation process at carbon fiber microelectrode is loss of 1 electron per molecule. The electrode process is controlled mainly by diffusion. The chemical and electrochemical parameters of the investigated system were determined experimentally and verified theoretically via digital simulation method.
\end{abstract}

Keywords: cysteamine, convolutive voltammetry, chronoamperometry, micro disk electrode

\section{INTRODUCTION}

The unique properties of microdisk electrodes offer a number of particular advantages for their use in analytical applications. In the steady-state mass transport to the microdisk is dominated by quasi-hemispherical diffusion. As a consequence, the mass transport to and from the microdisk electrode surface is efficient, reproducible and insensitive to random convection. In analytical applications based on accumulation and stripping techniques this obviates the need for stirring during the preconcentration step, improves the precision of the measurement, and reduces analysis times. In addition, the small electrode surface area of the microdisk means that the double layer capacitance of the electrode is small, thus significantly reducing the charging current. As a consequence, the ratio of the steady-state Faradaic current to the non-Faradaic current is increased and the detection limit is enhanced. ${ }^{1}$

The small size of the electrodes also means that the currents passed at the microelectrode are small resulting in negligible ohmic drop ( $i R$ drop) even in the absence of a supporting electrolyte. ${ }^{2,3}$ This has dual advantages in analytical applications that sample preparation can be simplified and that the possibility of impurities from the added electrolyte is eliminated. Microelectrodes are thus particularly well-suited for trace analysis. $\mathrm{Pt}, \mathrm{Au}, \mathrm{Hg}$ and carbon microelectrodes have been used in stripping analyses for the determination of trace metals by a number of authors..$^{4-8}$ In contrast, studies using microelectrodes for the determination of organic species are far less numerous and are restricted to the use of carbon fiber microelectrodes. ${ }^{9-19}$

Cysteamine (2- mercaptoethylamin hydrochloride) is a thio-containing compound (Fig. 1) biologically important in living systems, ${ }^{20}$ as an

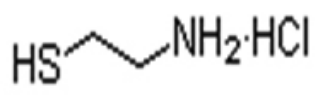

Figure 1

active site in the catalytic activity of enzyme and it's found in the structure of vasopressin an antidiuretic hormone. ${ }^{21}$ This substance is involved in a variety of important cellular functions, such as protein synthesis, detoxification and metabolism disorders of cysteamine metabolism include cystinosis, an antosomal recessive disease produced by a defect in lysosomal transport and cystinuria, a common heritable disorder of amino acids transport. ${ }^{22,23}$ Furthermore, plasma thiol groups have been shown to be susceptible to oxidative damage and, therefore, can serve as diagnostic markers for cardiovascular diseases. ${ }^{24}$ Cysteamine has several pharmaceutical applications; it is used in some antibiotics and for treatment of skin damages ${ }^{25}$ and as radio protective agent. ${ }^{26}$

Cysteamine $\{\mathrm{HCl}\}$ is currently used for cystinosis patients in an oral/systemic form or as an eye drop, at a concentration level of $0.5 \%$ and in a solution preserved with benzalkonium chloride. Cysteamine therapy has been shown to produce improved growth and stabilized renal function in pre-renal transplant cystinotics, without substantial toxicity. Cysteamine may also be used after glaucoma surgery, trabeculectomy or seton, to reduce scar tissue proliferation. ${ }^{27}$
Different analytical methods have been developed to quantify cysteamine and there metabolites in biological matrices (urine, human salivary, blood), pharmaceutical preparation and foods. The most commonly employed techniques are the chromatographic such as liquid chromatography (LC), ${ }^{28-}$ ${ }^{33}$ and gas chromatography (GC). ${ }^{34}$ Many of these methods require several manipulation steps which are time-consuming and use significant amounts of solvent, and they require sophisticated instrumentation and training. Considering that voltammetric techniques are relatively simple to apply, quite rapid and reasonably cheap, several procedures for quantification of cysteamine based on electrochemical methods have been developed.

Convolutive voltammetry was introduced in the early 1970 s to simplify the treatment of voltammetric data for analytical and kinetic applications. . $^{35-39}$ Convolutive voltammetry is more powerful in determining the electrochemical parameters as well as identifying the nature of electrode mechanism. To the best of our knowledge no convolutive voltammetry carried out on cysteamine at carbon fiber microdisk electrode.

The aim of this work is the identification of the electrode nature and determination of the chemical and electrochemical parameters of cysteamine at carbon fiber microdisk electrode using various voltammetric techniques combined with digital simulation method

\section{EXPERIMENTAL}

\subsection{Electrochemical cells}

Voltammetric experiments were carried out with a three electrode cell inside a Faraday cage. The working electrode was a $7.5 \mu \mathrm{m}$ ) diameter carbon fiber microdisk, platinum wire as counter electrode and the reference electrode was a saturated calomel electrode, SCE, all potentials are referenced to this electrode.

2.2. Reagents and solutions

Cysteamine (analytical grade) was used as supplied (Fluka, AG). All other chemicals were Merck pro-analysis grade and all solutions were prepared using purified water. The supporting electrolyte in voltammetric determination was $\mathrm{HClO}_{4}$ solution $(0.1 \mathrm{M})$.

2.3. Carbon fiber microdisk treatment

The surface of the carbon fiber microdisk electrode was polished mechanically with graded alumina powder of different sizes $(1,0.3-0.05 \mu \mathrm{m})$ Buehler, Lake Bluff, IL, USA) on a polishing cloth. In order to improve the repeatability of the treatment, an electrochemical cleaning of the electrode surface was also made by cycling the potential several times in $0.1 \mathrm{M} \mathrm{HClO}$ at a scan rate of $50 \mathrm{mV} / \mathrm{s}$ between 0.4 and $1.4 \mathrm{~V}$, until the blank cyclic voltammograms were reproducible. ${ }^{40}$ The effective electrode radius was determined by recording the steady-state diffusion limiting current, $I_{\text {ss }}$ from a $10 \mathrm{mM}$ solution of ruthenium(III) hexamine trichloride in $0.2 \mathrm{M} \mathrm{KCl}$. The radius of the electrode was estimated using the equation for the current at a microdisk $^{40,41}$

$$
I_{\mathrm{ss}}=4 n F D C^{\mathrm{b} r}
$$

where $r$ is the radius of the microdisk, $C^{b}$ the bulk concentration, $D$ the diffusion coefficient of the $\left[\mathrm{Ru}\left(\mathrm{NH}_{3}\right)_{6}\right]^{3+}\left(D=0.9 \times 10^{-9} \mathrm{~m}^{2} / \mathrm{s}^{40}\right.$ and the other 
symbols have their usual meanings.

\subsection{Procedures}

The electrochemical behaviour of $5.0 \times 10^{-4} \mathrm{M}$ cysteamine was studied in $\mathrm{HClO}_{4}$ solutions $(0.1 \mathrm{M})$ at carbon fiber microdisk electrode, using four voltammetric techniques: Cyclic voltammetry (CV), convolutive voltammetry, linear sweep voltammetry and chronoamperometry techniques combined with digital simulation technique. A known volume of cysteamine solutions, together with $0.1 \mathrm{M}$ of $\mathrm{HClO}_{4}$ solution, was purged with purified nitrogen for $2 \mathrm{~min}$. The electrode surface was polished between two consecutive scans. The scan was conducted from $0.4 \mathrm{~V}$ to $1.4 \mathrm{~V}$.

\subsection{Generation of theoretical voltammograms}

Digital simulation of the data for cyclic voltammetric experiments was performed on PC computer using EG \& G Condesim software package. The simulation procedure was carried out using finite differences techniques. ${ }^{42}$ Algorithms for the simulation program were coded and implemented into the condesim software package supplied by EG \& G. A direct test of the determined electrochemical parameters was performed by generating the simulated cyclic voltammogram of cycteamine using the average values of electrochemical parameters extracted experimentally and comparing it with the voltammogram recorded experimentally.

\section{RESULTS AND DISCUSSION}

\subsection{Cyclic voltammetry study}

In this work, a carbon fiber microdisk electrode was used in order to obtain some information of the electrochemical oxidation behaviour of cysteamine. The cyclic voltammograms of $5.0 \times 10^{-4} \mathrm{M}$ cysteamine in $0.1 \mathrm{~mol} / 1 \mathrm{HClO}_{4}$ solution displays oxidation steady state limiting current at sweep rate of 0.02 V/s (Fig. 2). The anodic scan yields a current plateau, at the scan rate until $v$ $\leq 1 \mathrm{~V} / \mathrm{s}$. The diffusion coefficient of the cysteamine was determined using Eq. (1) and found to be $5.62 \times 10^{-10} \mathrm{~m}^{2} / \mathrm{s}$.

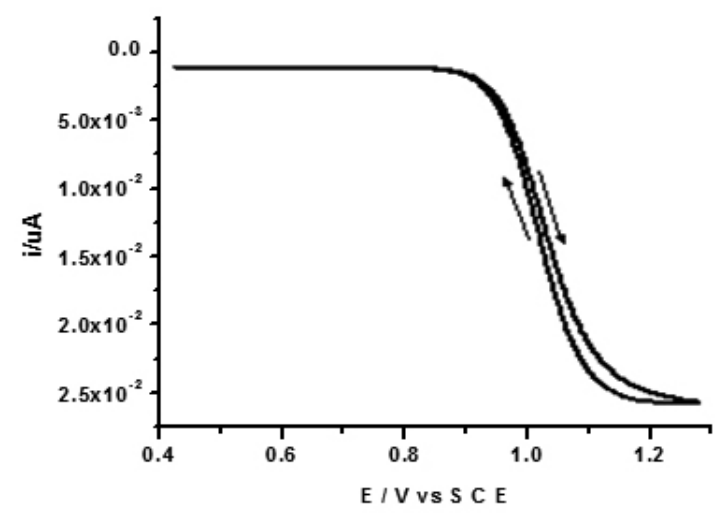

Figure 2: Cyclic voltammogram of $5 \times 10^{-4} \mathrm{M}$ solution of cysteamine recording in $0.1 \mathrm{M} \mathrm{HClO}_{4}$ at a carbon fiber microdisk electrode at scan rate of $0.02 \mathrm{~V} / \mathrm{s}$.

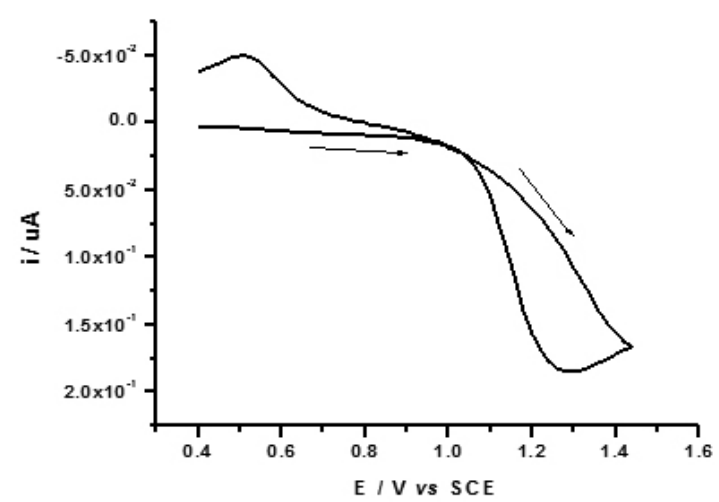

Figure 3: Cyclic voltammogram of $5 \times 10^{-4} \mathrm{M}$ solution of cysteamine recording in $0.1 \mathrm{M} \mathrm{HClO}_{4}$ at a carbon fiber microdisk electrode at scan rate of $10.0 \mathrm{~V} / \mathrm{s}$

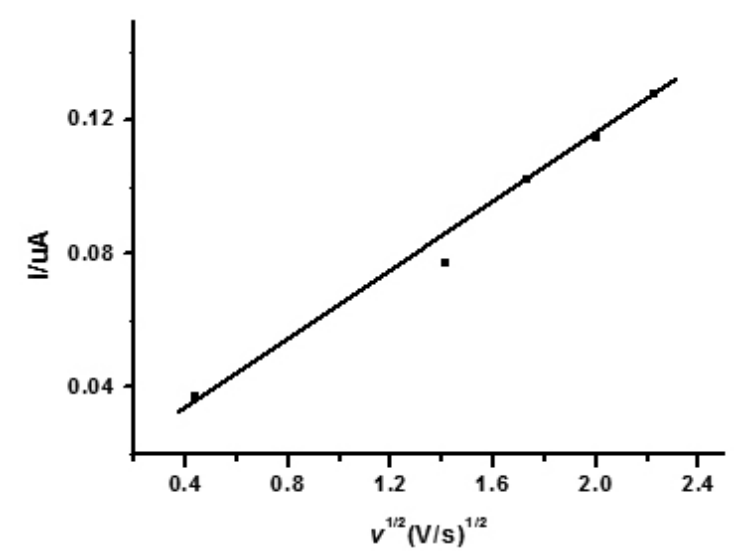

Figure 4A: Presentation of peak current $\left(i_{\mathrm{p}}\right)$ of cysteamine versus square $\operatorname{root}\left(v^{1 / 2}\right)$ of scan rate at high scan rate $(2-5 \mathrm{~V} / \mathrm{s})$.

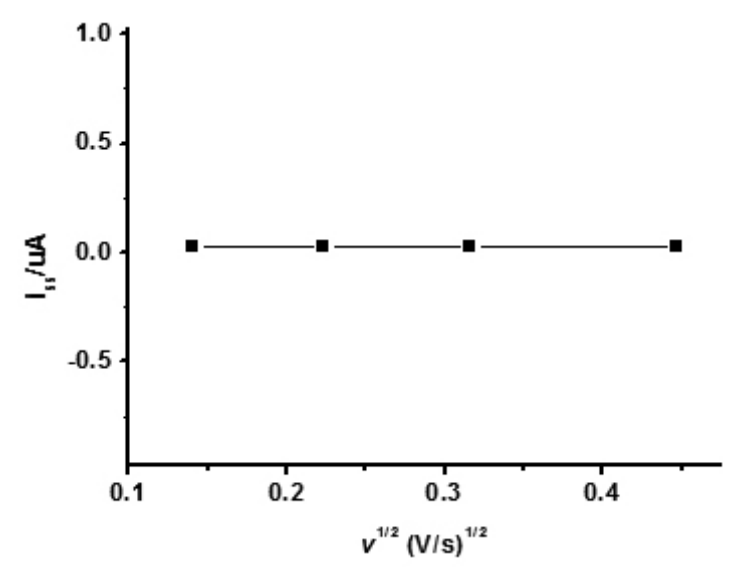

Figure 4B: Presentation of steady state current $\left(i_{\mathrm{ss}}\right)$ of cysteamine versus square root of scan rate $\left(v^{1 / 2}\right)$ at low scan rate $(0.005-0.2 \mathrm{~V} / \mathrm{s})$.

At sweep rate of $10 \mathrm{~V} / \mathrm{s}$ the voltammogram shows a well defined oxidative peak at $1.28 \mathrm{~V}$ on the top of the sigmoidal wave expected for a simple diffusion controlled process at a microdisk electrode (Fig. 3). On the return scan the wave deviates from sigmoidal shape as indicated from the appearance of the reductive peak in the backward direction (Fig. 3). The effect of the scan rate on the peak current, $i_{\mathrm{p}}$, was investigated over the range of $2-10 \mathrm{~V} / \mathrm{s}$. It was found that, $i$, increases with increasing the sweep rate and follows a simple linear relationship or square root relationship indicating that the peak current is determined by a diffusion process (Fig. 4A). At low sweep rate in the range of $0.005-0.2 \mathrm{~V} / \mathrm{s}$ the forward and return scan of the cyclic voltammogram gives a well defined sigmoidal wave of the type expected for a diffusion controlled processes at a microdisk electrode. The horizontal relationship between $i_{n}$ and $\mathrm{v}^{1 / 2}$ of the investigated system at sweep rate in the range $0.005-0.2 \mathrm{~V} / \mathrm{s}$ is shown in Fig. 4B. As indicated the cycles carried out within the low values of scan rates produced a horizontal line at sweep rate of $0.005-0.2 \mathrm{~V} / \mathrm{s}$ and linear relationship with the square root of high scan rate $>2 \mathrm{~V} / \mathrm{s}$. This indicates that the process at the surface of the electrode was mainly controlled by diffusion. The number of electrons was determined by the application of Randles and Sevcik mathematical ${ }^{43}$ and found to be equal to unity. As shown the cyclic voltammogram at sweep rate of $10 \mathrm{~V} / \mathrm{s}$ is similar to that obtained from conventional electrode i.e. exhibit peak shape cyclic voltammogram. This behaviour demonstrate that at large $v$ (short time) and conventional electrode radius $(r)$ exhibit planar (linear) diffusion or peaks shape, while at small $v$ (long time) and small electrode radius (r) produce non-planar (radial) diffusion or steady state.

The peak separations $\Delta E_{\mathrm{p}}$ between oxidative and reductive peaks were in the range $590-770 \mathrm{mV}$, indicating the slow nature of the charge transfer process (irreversible). The transfer coefficient, $\alpha$, was determined using the relationship $E_{\mathrm{p}}-E_{\mathrm{b} 2}=48 / \alpha \mathrm{n}_{\mathrm{a}}$ and found to be $0.3 \pm 0.05$. The ratio of $\mathrm{Q}_{\mathrm{b}}$ $/ \mathrm{Q}_{\mathrm{f}}$ was found to be less than unity but increase with increasing the sweep 
rate confirming the presence of chemical step after the charge transfer, i.e. $E C$ mechanism.

The electrode reaction of cysteamine can be proposed as following:

$$
\begin{aligned}
& \text { RSH.HCl } \leftrightarrow \mathrm{RS}^{*} \cdot \mathrm{HCl}+\mathrm{H}^{+}+\mathrm{e}^{-} \\
& 2 \mathrm{RS}^{*} . \mathrm{HCl} \rightarrow \mathrm{RSSR} .2 \mathrm{HCl}
\end{aligned}
$$

As indicated the chemical step may be due to the dimerization of $\mathrm{RS}^{*}$ to RSSR in irreversible process.

From the above results we conclude that, mass transport from the bulk to the electrode surface is one of the factors determining the shape of cyclic voltammograms and the magnitude of faradaic currents. The steady-state response arises because the electrolysis rate is equal to the rate at which molecules diffuse to the electrode.

\subsection{Convolutive voltammetry}

The convolution interface method introduced by Oldham ${ }^{35-37}$ and Saveant and co-workers ${ }^{38,39}$ allows simple determination of the surface concentration of a depolarizer from the current-time dependence measured during an electrochemical experiment. Originally this method was based on semiintegration of current with respect to time and it was applicable to processes involving semi-infinite linear diffusion of reactants.

The $I_{1}$ convolution is defined as follows: ${ }^{44,45}$

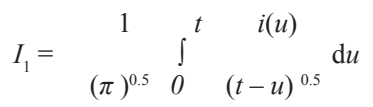

where $I_{1}$ is the convoluted current at the total elapsed time $(t)$, and $i(u)$ is the experimental current at time $u{ }^{46}$ The electron transfer of the oxidation process was found to be irreversible as indicated by the lack of overlay of the return sweep of the convoluted current on cyclic sweeping at scan rate of 10 $\mathrm{V} / \mathrm{s}$ (Figure 5). The diffusion coefficient $(D)$ of the investigated system was evaluated from the following relationship: ${ }^{46}$

$$
I_{\lim }=n F S D^{I / 2} C^{b},
$$

where $I_{\lim }$ is the limiting value achieved for $I_{1}$ when the potential is deriven to a sufficiently extreme value past the wave, and the other terms have their usual meanings.

The deconvoluted current is defined as. ${ }^{42,47}$

$$
e=\frac{\mathrm{d}^{1 / 2} I_{1}}{\mathrm{~d} t^{1 / 2}}=\mathrm{d} I_{1}
$$

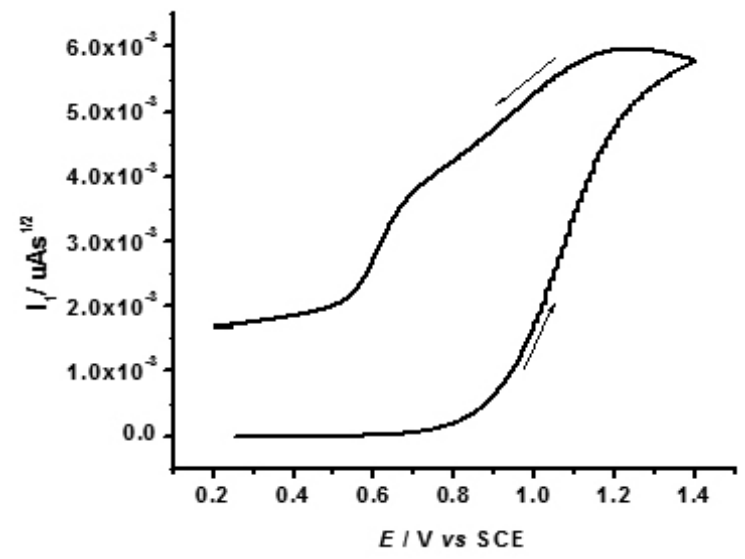

Figure 5: Convoluted current $\left(I_{1}\right)$ of cysteamine at scan rate of $10 \mathrm{~V} / \mathrm{s}$.

which consists of two mirror image peaks with a maximum and minimum amplitude alignment at $E_{1 / 2}$ value and the value of half peak width $W^{p}$ equals $3.526 R T / n F$ or $90.53 / n \mathrm{mV}$ in case of rapid electron transfer and $T=298 \mathrm{~K}$. Figure 6 indicates an example of the deconvoluted current $\left(d I_{1} / d t\right)$ versus the applied potential. The asymmetry of the forward and the reverse peaks indicates and confirms the $E C$ nature of the electrode mechanism. The peak located at 0.6 $V$ in the reverse scan of the deconvoluted voltammogram is due to the reduction of the oxidized form of cysteamine i.e. the overall electrochemical process of the electrooxidation step is $E C$ scheme. The value of the redox potential $E^{0}$ was determined from the average values of the forward and backward peak positions and is listed in Table 1 .

Table 1: Electrochemical parameters of the investigated cysteamine hydrochloride at carbon fiber microdisk electrode.

\begin{tabular}{|l|cccccc|}
\hline Parameters & \multicolumn{5}{|c|}{ Techniques } \\
& $\mathrm{CV}$ & conv & deconv. & Sim & LSV & CA \\
& & & & & & \\
\hline$k_{\mathrm{s}} \times 10^{6}$ & ---- & ---- & ---- & 2.4 & ---- & ---- \\
$\mathrm{m} / \mathrm{s}$ & & & & & & \\
$E^{0} / \mathrm{V}$ & ---- & --- & 0.921 & 0.921 & --- & ---- \\
$D \times 10^{10}$ & 5.61 & 5.53 & ---- & 5.62 & 5.53 & 5.71 \\
$\mathrm{~m}^{2} / \mathrm{s}$ & & & & & & \\
$\alpha$ & 0.31 & ---- & ---- & 032 & ---- & --- \\
$\mathrm{k}_{\mathrm{c}}, \mathrm{s}^{-1}$ & & & & 3.1 & \\
\hline
\end{tabular}

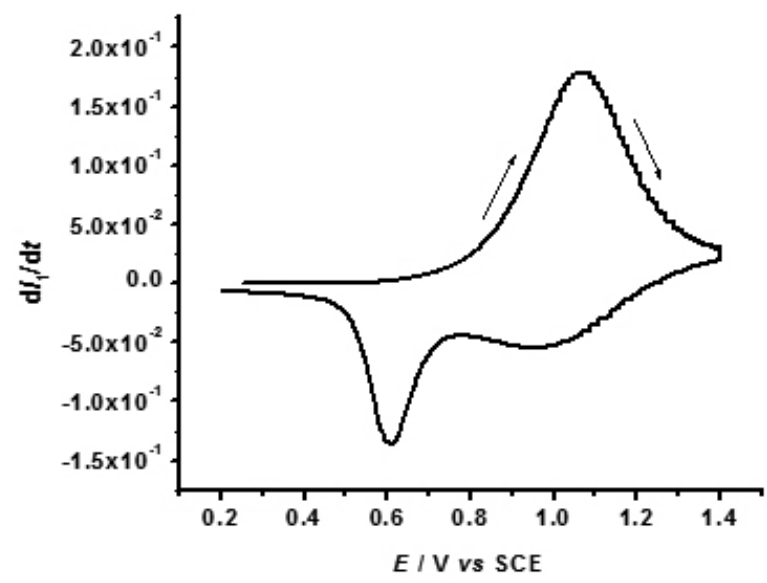

Figure 6: deconvoluted current of cysteamine at scan rate of $10 \mathrm{~V} / \mathrm{s}$.

The anodic half peak width $\left(W^{p}\right)$ was taken as a simple route for characterization of the nature of electron transfer. ${ }^{47}$ The values of $W^{p}$ were found to be equal $165-383 \mathrm{mV}$ at $v$ in the range of $0.1-10 \mathrm{~V} / \mathrm{s}$ (Table 2), confirming the slow nature of electron transfer of the investigated system.

\subsection{Digital simulation}

Figure 7 illustrates the agreement between simulated and experimental one at $v=10 \mathrm{~V} / \mathrm{s}$ confirming the suggested electrode mechanism as well as the accuracy of the determined electrochemical parameters listed in Table 1. The values of the standarad heterogeneous rate constant $(\mathrm{k})$ and the homogeneous chemical rate constant $\left(k_{c}\right)$ which exhibit good matching between experimental and theoretical cyclic voltammograms are $2.4 \times 10^{-6} \mathrm{~m} / \mathrm{s}$ and $3.1 / \mathrm{s}$ respectively (Table 1).

\subsection{Linear sweep voltammetry}

Fig. 8A shows the recorded linear sweep voltammogram for $1 \times 10^{-4} \mathrm{M}$ cysteamine when scanning the potential from 0.4 to $1.4 \mathrm{~V}$ at $0.05 \mathrm{~V} / \mathrm{s}$. The corresponding limiting currents, $I_{\mathrm{ss}}$, increase linearly with the cysteamine concentration. and shown in Fig. 8B. From the slope of the plot we calculated the diffusion coefficient of the cysteamine $\left(5.53 \times 10^{-10} \mathrm{~m}^{2} / \mathrm{s}\right)$. 
Table 2: wave characteristics extracted from $\mathrm{CV}$ and deconv of the investigated compound at various values of sweep rates.

\begin{tabular}{|l|cccc|}
\hline Sweep rate & $i_{\mathrm{p}}$, & $E_{\mathrm{p}}-E_{\mathrm{p} / 2}$, & $\Delta E_{\mathrm{p},}$ & $W^{\mathrm{p}}$, \\
$v, \mathrm{~V} / \mathrm{s}$ & $\mathrm{uA}$ & $\mathrm{mV}$ & $\mathrm{mV}$ & $\mathrm{mV}$ \\
\hline 1 & 0.060 & 101 & ---- & 165 \\
2 & 0.072 & 120 & 590 & 201 \\
5 & 0.095 & 143 & 680 & 295 \\
10 & 0.185 & 167 & 770 & 383 \\
\hline
\end{tabular}

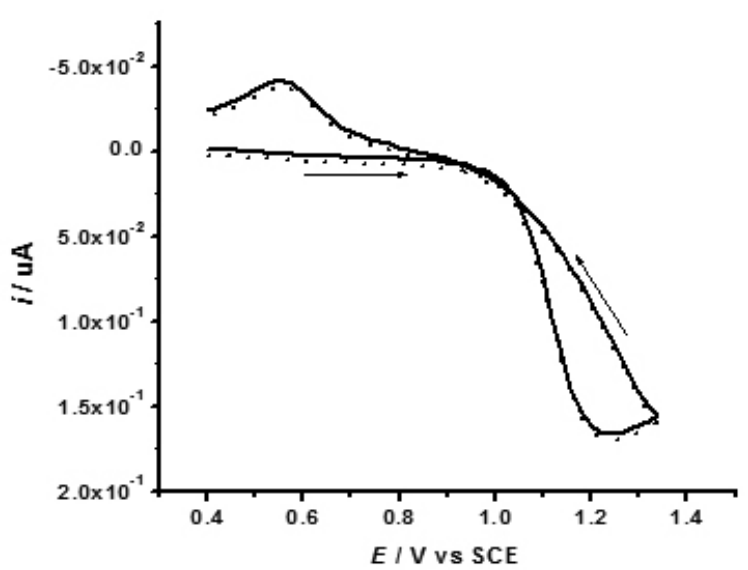

Figure 7: Matching between experimental (— voltammograms $(. . . .$.$) at scan rate of 10 \mathrm{~V} / \mathrm{s}$.

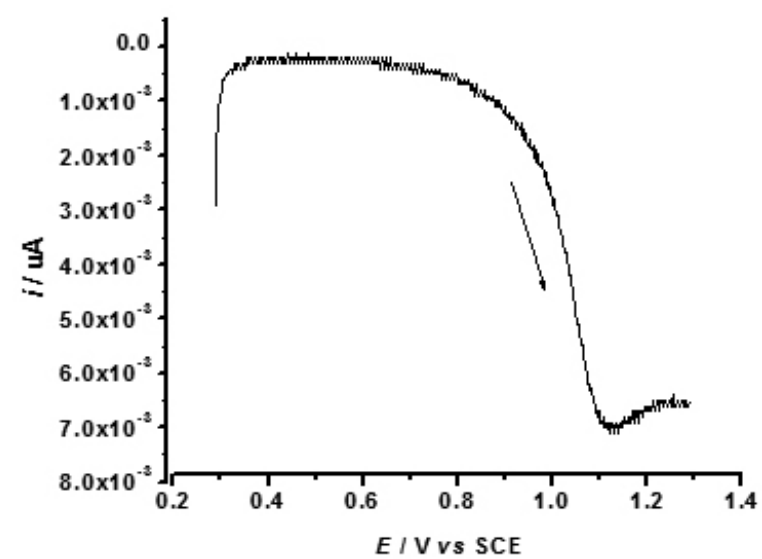

Figure 8A: Linear sweep voltammogram at scan rate of $0.5 \mathrm{~V} / \mathrm{s}$.

The influence of the scan rate on the anodic peak current $\left(i_{\mathrm{p}} \mathrm{a}\right)$ was studied within the range $0.010-10 \mathrm{~V} / \mathrm{s}$. It was found that the linear sweep voltammetry produced a horizontal line at $\mathrm{v} 0.005-0.1 \mathrm{~V} / \mathrm{s}$ and produce linear relationship with the square root of the scan rate at high values of $v$. This indicates that the process at the surface of the electrode was mainly controlled by diffusion and following:

$$
-i_{\mathrm{pa}}\left(\times 10^{-5}\right)=2.93 \times 10^{-1} v^{1 / 2}+6.18 \times 10^{-6}
$$

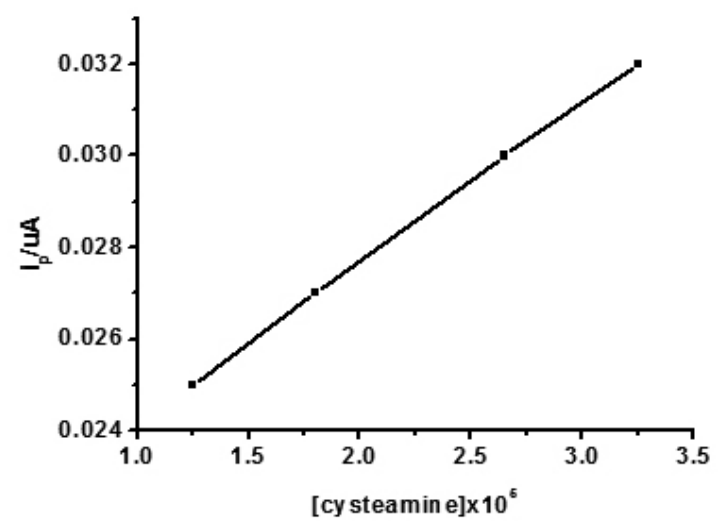

Figure 8B: presentation of peak current versus concentration of cysteamine from linear sweep voltammograms at scan rate of $0.5 \mathrm{~V} / \mathrm{s}$.

where $i_{\mathrm{p}}$ a is the peak current of cysteamine (Ampere); $v$ is the scan rate $(\mathrm{mV} / \mathrm{s})$, with a correlation coefficient $(r)$ of 0.997 . The number of electrons was determined by the application of Randles and Sevcik mathematical equation. ${ }^{48}$

\subsection{Chronoamperometry}

After knowing the electrooxidation behaviour of cysteamine, a chronoamperometry technique was used to evaluate the influence of time on the chronoamperogram behaviour. Figure 9A shows a typical chronoamperogram obtained for cysteamine in $0.1 \mathrm{M} \mathrm{HClO}_{4}$ solution at potential step $50 \mathrm{mV}$ i.e., initial potential, $E_{\mathrm{i}}=0.70 \mathrm{~V}$ and final potential, $E_{\mathrm{f}}=0.75 \mathrm{~V}$. Figure $9 \mathrm{~B}$ shows the presentation of $i$ vs $t^{-1 / 2}$, which indicates good linearity of the $i$ vs. $t^{-1 / 2}$ plot. It is important to notice that for the lowest $t^{-1 / 2}$ values (i.e., the largest times) the current tends to a value clearly different from zero, which evidences the absence of a total overlapping of the individual diffusion layers.

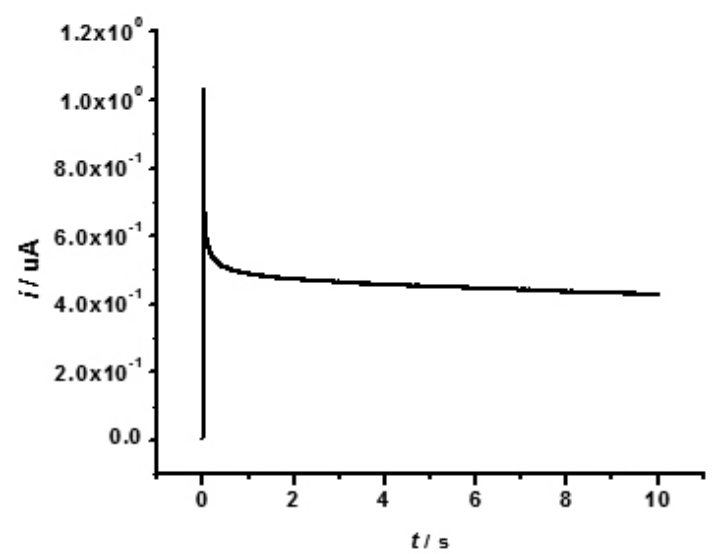

Figure 9A: Chronoamperogram (CA) of cysteamine at microdisk electrode.

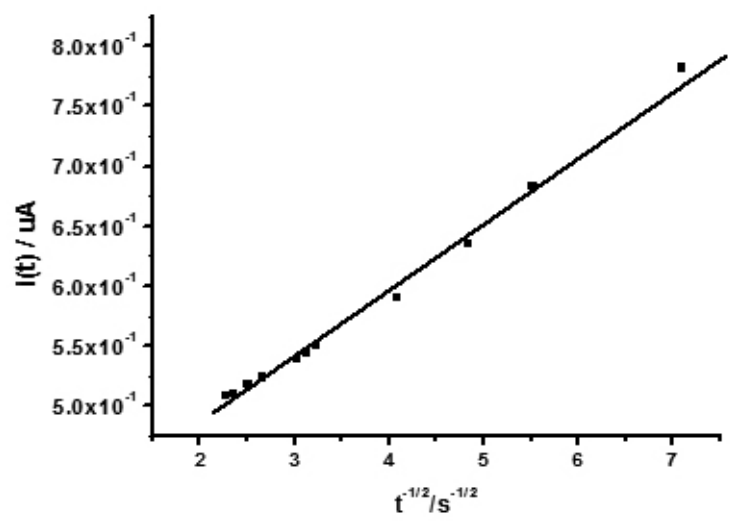

Figure 9B: presentation of current $i(\mathrm{t}) v_{S} t^{-1 / 2}$ of cysteamine from chronoamperogram at microdisk electrode. 
It was established that the microdisk electrode share the advantage of spherical microelectrodes in that quasi-spherical diffusion fields are established in relatively short lengths of time. Oldham et $\mathrm{al}^{49-51}$ simply compared the current response of a microdisk to that of a microsphere. They have shown that the diffusion controlled current density at a microdisk of radius $(r)$ is the same as that a sphere of radius $r$, given by $r=\pi r / 4$. Thus an expression for the current density at a microdisc electrode can obtained using equation (7) which describes the current density $(j)$ at a microsphere as following:

$$
j={\underset{r}{\mathrm{~s}}}_{r^{2}}^{n F D c^{\mathrm{b}}}+(\pi t)^{1 / 2}
$$

where $(n)$ is the number of electrons transferred in the redox reaction, $(F)$ is the Faraday's constant, $\left(r_{\mathrm{s}}\right)$ the radius of the sphere, $(D)$ the diffusion coefficient for electroactive species and $\left(c^{\mathrm{b}}\right)$ its bulk concentration. Then making the substitute $r_{\mathrm{s}}=\pi r / 4$,

$$
j=\underset{\pi r}{4 n F D c^{\mathrm{b}}}+\begin{gathered}
n F D^{1 / 2} c^{\mathrm{b}} \\
\pi t^{1 / 2}
\end{gathered}
$$

The current is obtained by multiplying equation (7) by $\pi r^{2}$, the area of the microdisk, as:

$$
i=4 n F D c^{\mathrm{b}} r+\begin{gathered}
n F D^{1 / 2} \pi^{1 / 2} c^{\mathrm{b}} r^{2} \\
t^{1 / 2}
\end{gathered}
$$

Eq. (8) indicates a linear relationship between the transient current and the reciprocal square root of time. The intercept $A$ and the slope $S$ of $i$ vs. $t^{-1 / 2}$ are:

$$
\begin{aligned}
& A=4 n F r D c^{\mathrm{b}}, \\
& S=n F D^{1 / 2} \pi^{1 / 2} c^{\mathrm{b}} r^{2} .
\end{aligned}
$$

From the ratio of $A / S$, the diffusion coefficient can be calculated as

$$
D^{1 / 2}=\left(A \pi^{1 / 2} r / 4 s\right)
$$

Eq. (11) indicates that $D$ can be obtained without the knowledge of $n$ and $c^{\mathrm{b}}$ provided $r$ is known. Thus obtaining $D$, leads to calculation of $n$ with knowing $c$ from the experimental intercept or slope using

Eq. (10) or Eq. (11). The value of the diffusion coefficient calculated from Eq. (11) is cited in Table 1.

\section{CONCLUSIONS}

On the basis of the electrooxidation of cysteamine at a carbon fiber microdisk electrode, four voltammetric techniques combined with digital simulation were used in order to investigate the electrochemical behaviour of cysteamine in 0.1 $\mathrm{M} \mathrm{HClO}_{4}$ solution. The relevant chemical and electrochemical parameters of the investigated cysteamine were determined. The effect of sweep rates on the cyclic voltammogram shape were carried out. The electrode mechanism was found to proceed as $E C$ scheme. The rate of charge transfer was found to be slow electron transfer.

\section{REFERENCES}

1. Wehmeyer, K. R.; Deakin, M. R.; Wightman, R. M. Anal. Chem. 1985, 57, 1913.

2. Daniele, S.; Baldo, M. A.; Ugo, P.; Mazzocchin, G. A. Anal. Chem. Acta. 1989, 9, 219.

3. Wong, D. K. Y.; Ewing, A. G. Anal. Chem. 1990 , 62, 2697.

4. Wang, J.; Hocevar, S. B.; Deo, R. P.; Ogorevc, B. Electrochem Commun. 2001, 3, 352 .

5. Hua, C.; Jagner, D.; Renman, L. Anal. Chim. Acta. 1987, 201, 263.

6. Huiliang, H.; Jagner, D.; Renman, L. Anal. Chim. Acta.1987, 202, 117.

7. Huiliang, H.; Jagner, L.; Renman, L. Anal. Chim. Acta. 1987, 202,123.

8. Bartlett, P. N.; Denuault, G.; Sousa, M. F. B. Analyst. 2000, 125,1135.

9. Blanco, M. H.; Quintana, M. D.; Hernandez, L. Fresenius J. Anal. Chem.
1999, 364, 254.

10. Cai, X. H.; Rivas, G.; Farias, P.A. M.; Shiraishi, H.; Wang, J.; Palecek, E. Electroanalysis. 1996, 8, 753 .

11. De Armentia, C. L.; Sampedro, C.; Goicolea, M. A.; De Baligera, Z. G.; Rodriguez, E.; Barrio, R. J. Electroanalysis. 1999, 11, 1222.

12. De La Huebra, M. J. G.; Hernandez,P.; Nieto, O.; Ballesteros, Y.; Hernandez, L. Fresenius J. Anal. Chem. 2000, 367, 474.

13. De La Huebra, M. J. G.; Hernandez, P.; Ballesteros, Y.; Hernandez, L. Talanta. 2001, 54, 1077

14. Fung, Y. S.; Mak, J. L. L. Electrochim. Acta. 1999, 44, 3855.

15. He, Y. N.; Chen, H. Y. Electroanalysis. 1997, 9, 1426.

16. Hernandez, P.; Patron, F.; Hernandez, L. Electroanalysis. 1997, 9, 1372.

17. Hern'andez, L.; Hern'andez, P.; Patron, F. Anal. Chim. Acta. 1996, $327,117$.

18. Hern'andez, P.; Patron, F.; Ballesteros, Y.; Hern'andez, L. Electroanalysis. 1997, 9, 235.

19. Wang, J.; Cai, X. H.; Fernandes, J. R.; Grant, D. H.; Ozsoz, M. J Electroanal. Chem. 1998, 441, 167.

20. Teixeira, M. F. S.; Dockal, E. R.; Cavalheiro, E. T. G. Sensors and Actuators B. 2005, 106, 619

21. Amini, M. K.; Khorasani, J. H.; Khaloo, S. S.; Tangestaninnejad, S. Anal. Biochem. 2003, 320, 32.

22. Lau, C.; Qin, X.; Liang, J.; Lu, J. Anal. Chim. Acta. 2004, 514, 45.

23. Ruiz-Díaz, J. J. J.; Torriero, A. A. J.; Salinas, E.; Marchevsky, E. J.; Sanz, M. I.; Raba, J. Talanta. 2006, 68, 1343.

24. Ueland, P. M.; Refsum, H.; Brattstrom, L. In: Francis R B, Jr. (Ed.) Atherosclerotic Cardiovascular Disease, Hemostasis, and Endothelial Function, Marcel Dekker, New York, 1992; pp. 183.

25. Wring, S. A.; Hart, J. P.; Birch, B. J. Analyst. 1989, 117, 1563.

26. Kulys, J.; Drungiliene, A. Anal. Chim. Acta. 1991, 243, 287.

27. Bjellaas, T.; Janak, K.; Lundanes, E.; Kronberg, L. Xenobiotica. 2005, 35, 1003.

28. Karlsson, K. M.; Spoof, L. E. M.; Eriluolo, J. A. O. Environ. Toxicol. 2005, 20,381.

29. Glowacki, R.; Gryglik, D.; Kusmierek, K.; Bold, E. Talanta. 2005, 66, 534.

30. Sunlonsuk, L. J. Pharm. Biomed. Anal. 2001, 25, 165.

31. Castagnola, M.; Congiu, D.; Denolli, G.; Di Núncio, A.; Fadda, M. B.; Melis, S.; Messana, L.; Misiti, F.; Murlas, R.; Olianas, A.; Piras, V.; Pittau, A.; Puddu, G. J. Chromatogr. B. 2001, 751, 153.

32. Bramanli, E.; Vecoli, C.; Neglia, D.; Pellegrini, M. P.; Raspi, G.; Barsacchi, B. Clin. Chem. 2005, 51, 1007.

33. Bosch, L.; Alegria, A.; Furre, R. J. Chromatogr. B. 2006, 831,176.

34. Orhan, H.; Commandeur, J. N. M.; Sahir, G.; Aypar, U.; Gahin, A.; Vermeulen, N. P. E. Xenobiotica. 2001, 34, 301.

35. Grenness, M.; Oldham, K. B. Anal. Chem. 1972, 44, 1121.

36. Oldham, K. B.; Zoski, C. G. J. Electroanal. Chem. 1983, 145, 265.

37. Myland, J. C.; Oldham, K. B.; Zoski, C. G. J.Electroanal. Chem. 1985 , 193, 3.

38. Nadjo, L.; Saveant, J. M.; Tessier, D. (1974) J Electroanal. Chem. 1974, 52,403 .

39. Saveant, J. M.; Tessier, D. J. Electroanal. Chem. 1977, 77, 225.

40. Wightmann, R. M.; Wipf, D. O. In: Bard, A. J. (Ed.), Electroanalytical Chemistry, Marcel Dekker New York, 1989; vol 15.

41. Montenegro, M. I.; Queiros, M. A.; Dashbach, J. L.; Microelectrodes: Theory and Applications Kluwer Academic Publishers Dordrecht; 1991.

42. El-Hallag, I. S.; Ghoneim, M. M.; Hammam, E. Anal. Chim. Acta. 2000, 414,173

43. Ordeig, C. E.; Banks, T. J.; Davis, J.; Del Campo, R.; Mas, F. X.; Munoz, Compton, R. G. Analyst. 2006, 131, 440.

44. Saveant, J. M.; Tessier, D. J. Electroanal. Chem. 1975, 65, 66.

45. Oldham, K. B.; Myland, J. C.; Zoski, C. G. J. Electroanal. Chem. 1989, 270,79 .

46. Carr, S. W.; Shaw, B. L. J. Chem. Soc. Dalton. Trans. 1986, 1815

47. Bhutti, N. K.; Subhani, M. S.; Khan, A. Y. Turk. J. Chem. 2005, 29, 659

48. Nicholson, R. S.; Shain, I. Anal. Chem. 1964, 36, 706.

49. Oldham, K. B. J. Electroanal. Chem. 1981, 122, 1

50. Newman, J. J. Electrochem. Soc. 1966, 113: 501.

51. Shoup, D.; Szabo, A. J. Electroanal. Chem. 1982, 140, 237. 